\title{
A CFD-based Approach to Predict Explosion Overpressure: A Comparison to Current Methods
}

\author{
C. Díaz-Ovalle, a, ${ }^{\mathrm{a},}$ A. López-Molina, ${ }^{\mathrm{b}}$ and R. Vázquez-Román \\ ${ }^{a}$ Tecnológico Nacional de México, Instituto Tecnológico de Roque, \\ Departamento de Ingenierías, Km 8 carretera Celaya-Juventino Rosas, \\ Celaya, 38110, Gto., MEXICO \\ bUniversidad Juárez Autónoma de Tabasco, División Académica \\ Multidisciplinaria de Jalpa de Méndez, Ingeniería en Petroquímica, \\ carretera Estatal Libre Villahermosa-Comalcalco Km. 27 s/n \\ Ranchería Rivera Alta, Jalpa de Méndez, 86205, Tab., MEXICO \\ 'Tecnológico Nacional de México, Instituto Tecnológico \\ de Celaya, Departamento de Ingeniería Química, Av. Tecnológico y A.G. \\ Cubas s/n, Celaya 38010, Gto., MEXICO
}

doi: 10.15255/CABEQ.2015.2244

Original scientific paper

Received: June 11, 2015 Accepted: December 5, 2016

\begin{abstract}
A CFD-based approach has been developed in this work to predict the overpressure produced during an explosion. An adiabatic exothermal reaction allows computing the explosion energy release. To validate the proposed CFD approach, overpressure predictions based on this methodology are compared with results produced with the TNObased method. It is demonstrated that the physics adopted in our model produces satisfactory predictions in the open area. The CFD simulations were carried out in the ANSYS CFX tool. The source of energy corresponds to the one produced by a stoichiometric proportion in reactants without energy generation. The explosion analysis considered that explosion occurs geometrically as a sequence of control volumes. Thus, the explosion in a volume is assumed to occur when the maximum pressure is achieved in the previous control volume. This way, the explosion is propagated and it is shown that it is equivalent to conventional predicting methods.
\end{abstract}

Key words:

CFD, explosion, overpressure, TNO method

\section{Introduction}

Explosions represent a hazard frequently found in the process industry. It consists of a rapid combustion of clouds producing a fast release of energy and gas expansion. Several explosion accidents have occurred in processing plants ${ }^{1}$. Human and economic losses justify the study of these accidents. Explosions are complex phenomena, which come from a sudden and rapid release of energy. This energy is dissipated in the form of heat radiation, acoustic waves, and waves of pressure. Explosions differ in characteristics depending on their source of generation, i.e. liquid at boiling, reactions out of control, and partially confined vapour ${ }^{2}$. The nature of explosions limits their study, due to: a) low occurrence time scale, b) uncertainty in the pressure wave, and c) uncertainty on the energy released. This last point has been estimated using first-principles of thermodynamic equilibrium for the system. This estimation includes the mechanical energy of

"Corresponding author: Christian Díaz-Ovalle. E-mail address: chdiaz@itroque.edu.mx; Phone: +52 4616115903 ext 141 the overpressure wave; however, both final and initial conditions of the system are typically unknown ${ }^{3}$. Thus, the prediction under thermodynamic equilibrium has involved experimental data.

A simplified model consists of mathematical correlations with parameters of occurrences under real-world scenarios. This kind of model can reliably represent explosions and determine the profile of overpressure. Among other, the TNT equivalence $^{4}$, TNO Multi-energy ${ }^{5}$ and Baker-Strehlow ${ }^{6}$. The results of these methods have been used to allocate process units and containment systems. Unfortunately, these models do not consider the effect of obstacles in the explosion. Despite this, these models have been used frequently due to their simplicity. Nowadays, the CFD (Computational Fluid Dynamics) predicts the phenomenon of explosion with greater precision accounting for the local environment such as confinement, congestion and blockage issues.

CFD has been applied in various areas of engineering. CFD represents a solution to the transport equations under their spatial discretization. In pro- 
cess safety, CFD has been used to predict gas and vapor dispersion ${ }^{7}$, blast from gas, pool fire ${ }^{8}$ and dust explosions $^{9-12}$. The transport equations include an energy source parameter when modelling explosions. CFD has solved problems of simulation for explosion under various physical scenarios such as: a) an obstructed environment equivalent to a porous system $^{13}$, b) a confined environment ${ }^{14,15}$ and c) venting ducts ${ }^{16}$. In these works, the results indicated that the strength of an explosion increases when increasing confinement and turbulence. Other works have incremented the complexity in the system due to dispersion scenarios with the allocation of the ignition source ${ }^{17}$. These approaches described congested with forced ventilation systems ${ }^{18}$, open systems ${ }^{19}$ and diverse geometries ${ }^{20}$.

CFD packages simulate the hydrodynamics of fluid in a variety of systems. The Gexcon package FLACS is becoming a leader in simulation of explosions. FLACS results have been validated with rigorous experiments in different scenarios ${ }^{21}$. This package predicts dispersions of dense gases under the $k-\varepsilon$ model of turbulence ${ }^{22}$. FLACS has estimated potential overpressures in several case studie ${ }^{23}$ and accidents ${ }^{24}$. Explosion calculation by FLACS considers combustion in a stoichiometric gas mix. During combustion, the fluctuations of species influence the kinetic energy dissipation due to the use of the Arrhenius model ${ }^{25}$. Temporal and spatial effects of scale re-evaluate the dissipation of energy under source terms. Turbulence kinetic energy and momentum equations include these source terms ${ }^{26}$. However, this approach requires the continuous consumption of gas in stoichiometric proportion, which can be considered as equivalent to a series of explosions in a time and space of low scale. This generates the prediction of an explosion as in an adiabatic system. The method TNO predicts overpressures at different levels of congestion, but in practical situations, the level of congestion cannot be defined in the majority of cases.

In this work, ANSYS-CFX simulations are carried out without using a term for energy generation. The explosion analysis is based on a series of control volumes without congestion, where the explosion in a control volume starts at the time of its maximum pressure to end up in a geometrical series of explosions.

\section{The proposed strategy}

The explosion produces three phenomena: combustion, turbulence, and gas expansion. Combustion starts as a flame whose instability increases the rate of combustion. This causes further expansion of gases and turbulence. Turbulence acceler- ates the burning, and the amount of fuel is proportional to the expansion of gases. This description corresponds to a cycle of power generation, which is characteristic for an explosion ${ }^{27,28}$.

The explosion occurs when gas concentration belongs to the interval defined by the lower and upper flammability limits. These limit values are specific for each fuel. In this analysis, the origin of the explosion is a cloud of gas fuel in dispersion. When the concentration achieves values inside the flammability limits, the cloud can be ignited. The whole cloud is then represented through a series of control volumes. These volumes allow describing the explosion as a series of consecutive explosions. Gas cloud data are taken at 7 minutes after having the release, as suggested for evacuation purposes.

The proposed strategy starts by simulating the gas dispersion using the code CFX 14.0 of ANSYS. The gas dispersion during 7 minutes is simulated, and the size of the cloud estimated. The next step corresponds to the activation of the adiabatic reaction assuming that the explosion occurs adiabatically in the called first volume of control. This first volume corresponds to the one where ignition is expected to be produced. Then, the explosion is modelled in a process simulator (ASPEN Plus 7.2 in this case) to estimate the resulting temperature, pressure, and mass composition in this volume. These values are plugged into the CFD simulation to obtain the effect on surrounding volumes. When conditions for explosion in surrounding control volumes are achieved, explosions are produced, and the process simulator is used to calculate again the resulting conditions. The procedure is repeated until no more explosions can be produced in the whole system. Figure 1 shows graphically the proposed methodology.

\section{CFD model}

CFD is used in this work to describe two scenarios. The first case corresponds to the cloud generation during the gas release, while the second case corresponds to modelling the escalation of the first explosion into radial explosions. Both cases correspond to transient simulation with compressible fluids, and the governing equations are identical for both scenarios, i.e. conservation of mass, momentum, energy, and species. These equations are given in Table 1 . The main variables are: $\mathbf{v}$, velocity vector, $P$, pressure, $\boldsymbol{\tau}$, shear stress tensor, $\mathbf{g}$, gravitational acceleration vector, $T$, temperature, $\mathbf{q}$, heat flux vector, $Y$, mass fraction per specie $i$. The main calculated properties are: $\rho$, density, $C_{P}$, specific heat capacity, $D_{i j}$, kinematic diffusivity of components $i-j$. The kinematic diffusivity is calculated by: 


$$
D_{i j}=\frac{a T^{1.5}}{b+c T}, i \neq j
$$

where $a, b$ and $c$ are correlation parameters for the binary system $i-j$.

The numerical solution of the governing equations is rather complicated. The nonlinearities in the momentum equation are due to the turbulence ${ }^{29}$. A wall adjacent to the fluid generates turbulence, which is treated under theories of scale and it should include a model for energy dissipation. Turbulence theory has a number of models based on different assumptions. The $\kappa-\varepsilon$ model contains two equations, which are appropriate for an open space with low wall effect. The standard $\kappa-\varepsilon$ model has been described by Launder and Sharma ${ }^{30}$, and it includes a variation in the turbulent kinetic energy, $\kappa$ :

$$
\frac{\partial \kappa}{\partial t}+\mathbf{v} \cdot \nabla \kappa=\boldsymbol{\tau}: \nabla \mathbf{v}-\varepsilon+\nabla \cdot\left(\left(v+v_{T}\right) \nabla \kappa\right)
$$

and the variation of the turbulence dissipation, $\varepsilon$

$$
\frac{\partial \varepsilon}{\partial t}+\mathbf{v} \cdot \nabla \varepsilon=1.44 \frac{\varepsilon}{\kappa} \boldsymbol{\tau}: \nabla \mathbf{v}-1.92 \frac{\varepsilon^{2}}{\kappa}+\nabla \cdot\left(\left(v+\frac{v_{T}}{1.3}\right) \nabla \varepsilon\right)(3)
$$

where $v$ is the kinematic viscosity and $v_{T}$ is the turbulent kinematic viscosity that is calculated by:

$$
v_{T}=0.09 \frac{\kappa^{2}}{\varepsilon}
$$

The solution of this equation is possible in all CFD codes. The following section describes the scenarios considered in the dispersion conditions and the characteristics of the CFD-based approach.

\section{Case study}

The solution of the governing equations quantify the gas dispersion and the dissipation of an explosion. The solution starts with the conventional

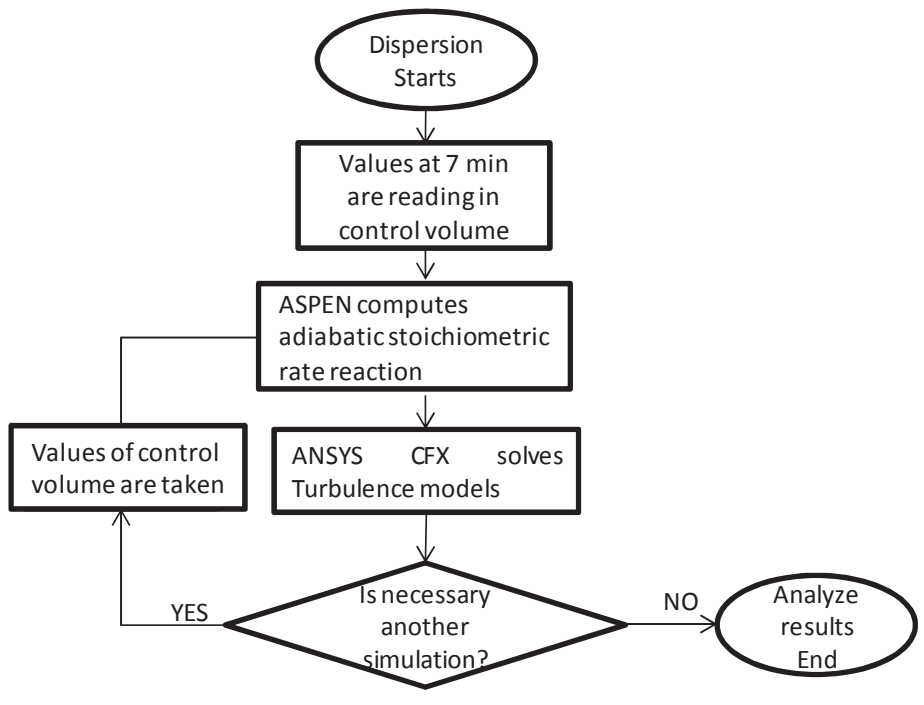

Fig. 1 - Schematic representation of the proposed methodology

strategy of CFD in the ANSYS Workbench. Thus, the strategy includes: development of the geometry, set-up of mesh, definition of the scenario, and numerical solution. The cloud dispersion is represented in an open geometry. The geometry mesh includes tetrahedral elements $(20,084$ nodes and 91,383 elements) and hexahedral elements $(27,054$ nodes and 15,265 elements. The mesh metric quality was obtained for skewness, aspect ratio, and orthogonal quality. The skewness indicated how close the cell size approached the optimum cell size in a circumsphere. A value close to zero is the most desirable, and the skewness value for the dispersion zone was 0.274 . The aspect ratio is defined as the relationship between the length of the longest side and the length of the shortest. Values lower than 40 are considered acceptable, and the aspect ratio value for the dispersion zone was 1.957. The orthogonal quality indicated the minimum value of the orthogonal relation between $(\mathrm{A}, \mathrm{f})$ and $(\mathrm{A}, \mathrm{c})$, where

Table 1 - Governing equations

\begin{tabular}{cl}
\hline Equation & Description \\
\hline$\frac{\partial \rho}{\partial t}=\nabla \cdot \rho \mathbf{v}$ & Continuity \\
$\frac{\partial}{\partial t}(\rho \mathbf{v})=-\nabla \cdot \rho \mathbf{v} \mathbf{v}-\nabla P-\nabla \cdot \boldsymbol{\tau}-\rho \mathbf{g}$ & Momentum conservation \\
$\frac{\partial}{\partial t}\left(\rho C_{P} T\right)=-\nabla \cdot\left(\rho C_{P} T \mathbf{v}\right)-\nabla \cdot \mathbf{q}-\boldsymbol{\tau}: \nabla \mathbf{v}$ & Energy conservation \\
$\frac{\partial}{\partial t}\left(\rho Y_{i}\right)+\nabla \cdot\left(\rho Y_{i} \mathbf{v}\right)=-\nabla \cdot \mathbf{J}_{\mathbf{i}}$ & Specie i conservation \\
\hline
\end{tabular}




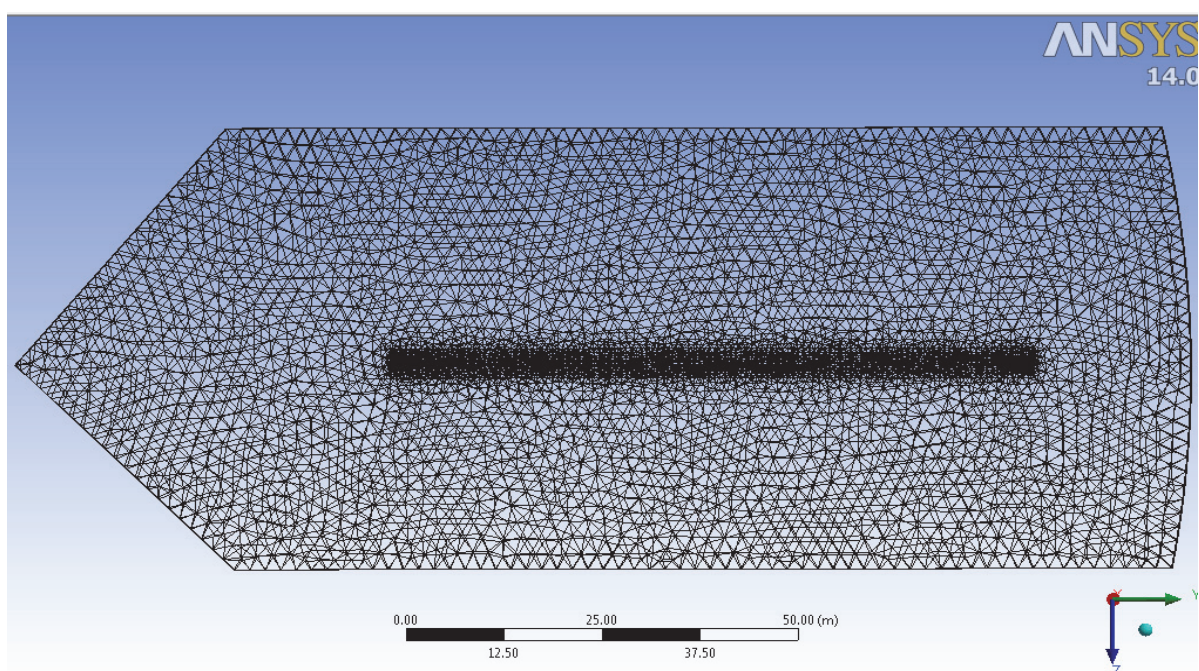

Fig. 2 - Top view of the meshing for gas dispersion scenario

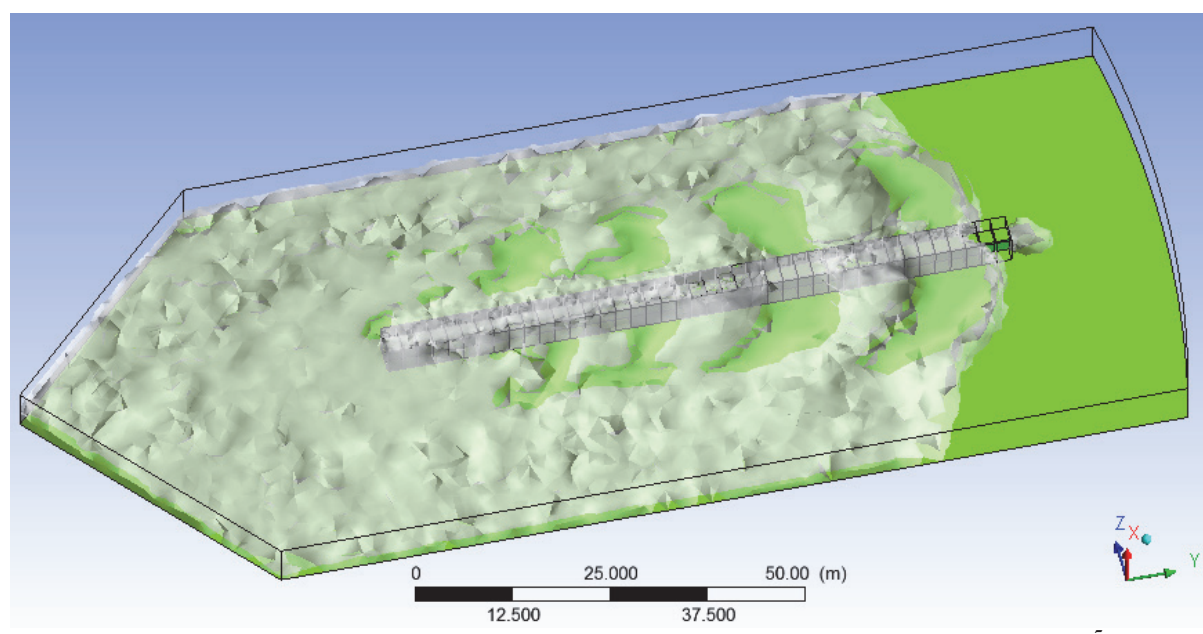

Fig. 3 - Propane cloud at 7 min, iso-surface with mass fraction of $5 \cdot 10^{-5}$

$A$ is the face normal vector, $\mathrm{f}$ is a vector from the centroid of the cell to the centroid of the face, and c is a vector from the centroid of the cell to the centroid of the adjacent cell. The most desirable for these cases is a value close to 1 , and the orthogonal quality value for the dispersion zone was 0.835 . Figure 2 shows a top view of the mesh for the gas dispersion.

The source of emission is propane, and its features are: a) flow of $1 \mathrm{~kg} \mathrm{~s}^{-1}$, b) temperature of 288 $\mathrm{K}$, and c) discharge through a pipe of $0.0254 \mathrm{~m}$ of diameter at $1 \mathrm{~m}$ above floor level. The Peng-Robinson equation of state is used to model the gas behavior. The atmosphere is standard with the following values: a) temperature $298 \mathrm{~K}$, b) pressure $101354 \mathrm{~Pa}$, and c) 0.233 mass fraction for $\mathrm{O}_{2}$ and the rest being $\mathrm{N}_{2}$. Terrain roughness is considered as $0.0001 \mathrm{~m}$. This scenario does not consider the effect of wind, while viscosity and thermal conductivity have the standard values for air. Kinematics diffu- sivity follows the expression (1), and parameters have values of: $a=5.826 \cdot 10^{-5} \mathrm{~m}^{2} \mathrm{~s}^{-1}, b=1.8033$ $\mathrm{K}^{0.5}$, and $c=-45.1061 \mathrm{~K}^{1.5}$. The solution for dispersion took increments of time variables until $7 \mathrm{~min}$. Figure 3 shows the fraction of $5 \cdot 10^{-5}$ for propane after running $7 \mathrm{~min}$ of dispersion, and Figure 4 shows the concentration and pressure profiles.

A total of eleven control volumes, cubes with 2 $\mathrm{m} /$ side, were considered. A volume for the neighborhood was also included. This way, control volumes were immersed in the neighborhood. The mesh for this geometry had 18,550 nodes and 12,338 hexahedron elements. Figure 5 shows the mesh using two perspectives.

\section{Results and discussion}

The dispersion generated a cloud of $80 \mathrm{~m}$ in length. It required the use of 40 control volumes; however, 11 control volumes were applied to save 


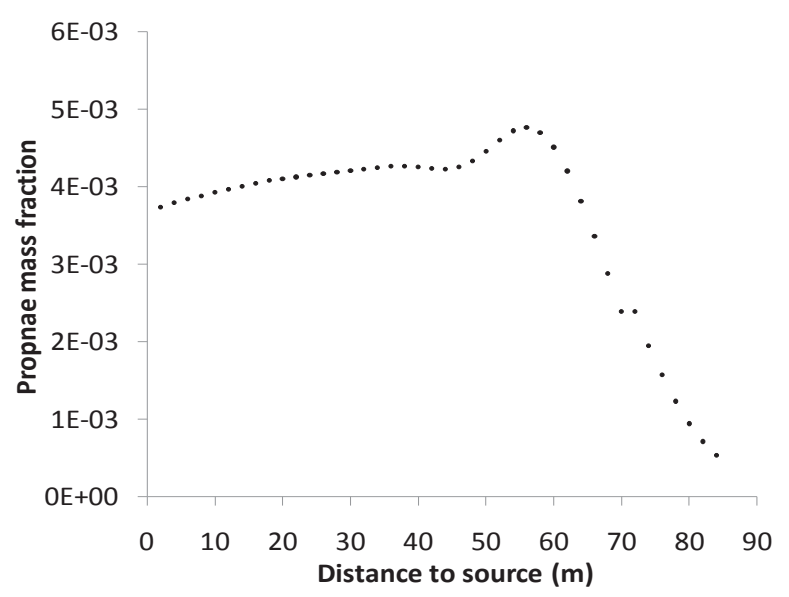

a

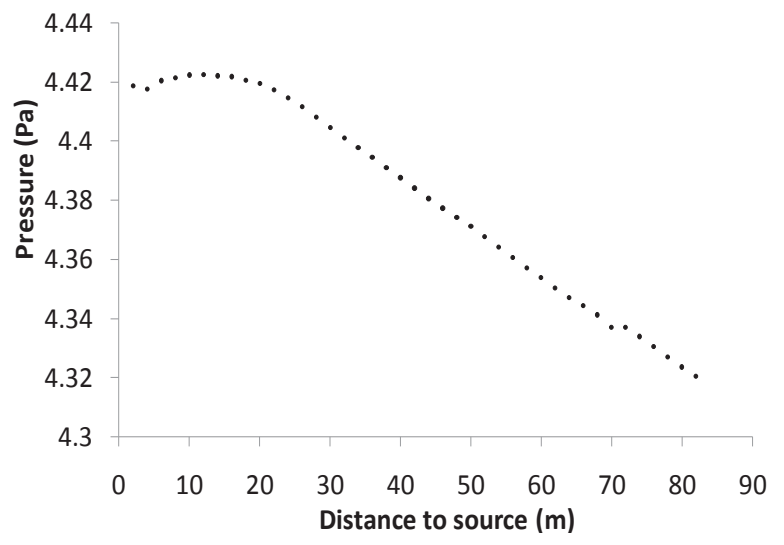

b

Fig. 4-Cloud profiles: a) propane mass fraction, b) pressure

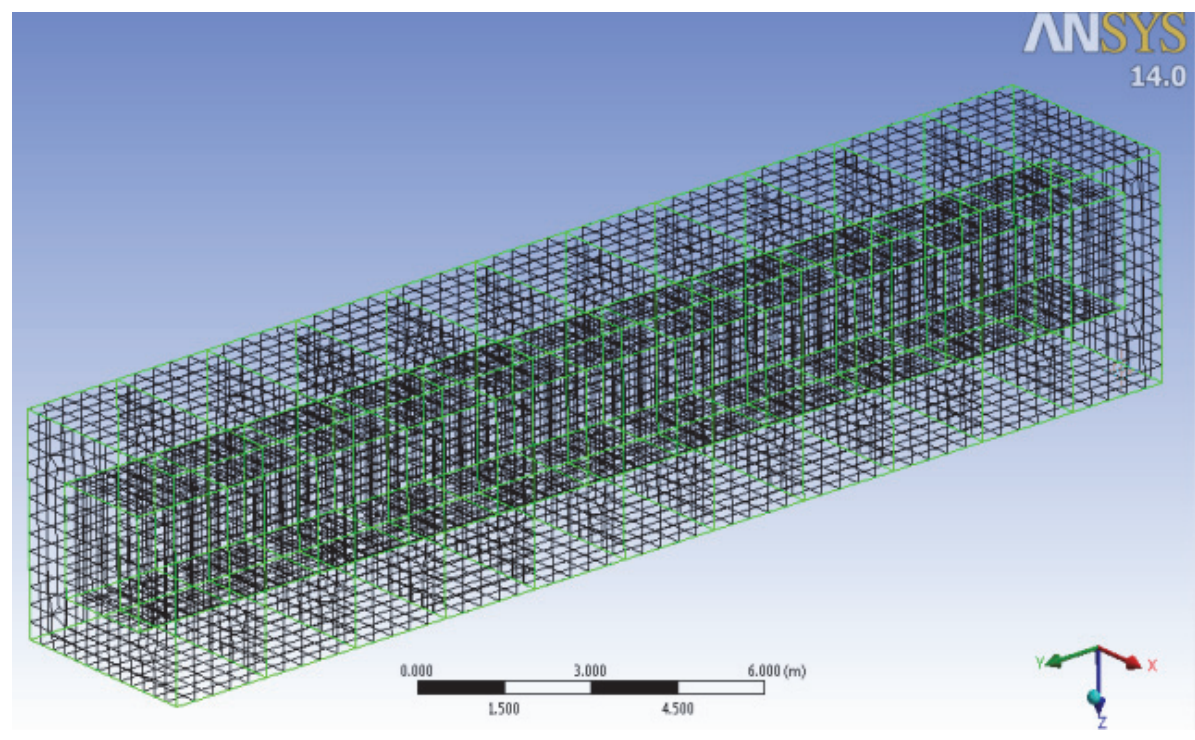

a

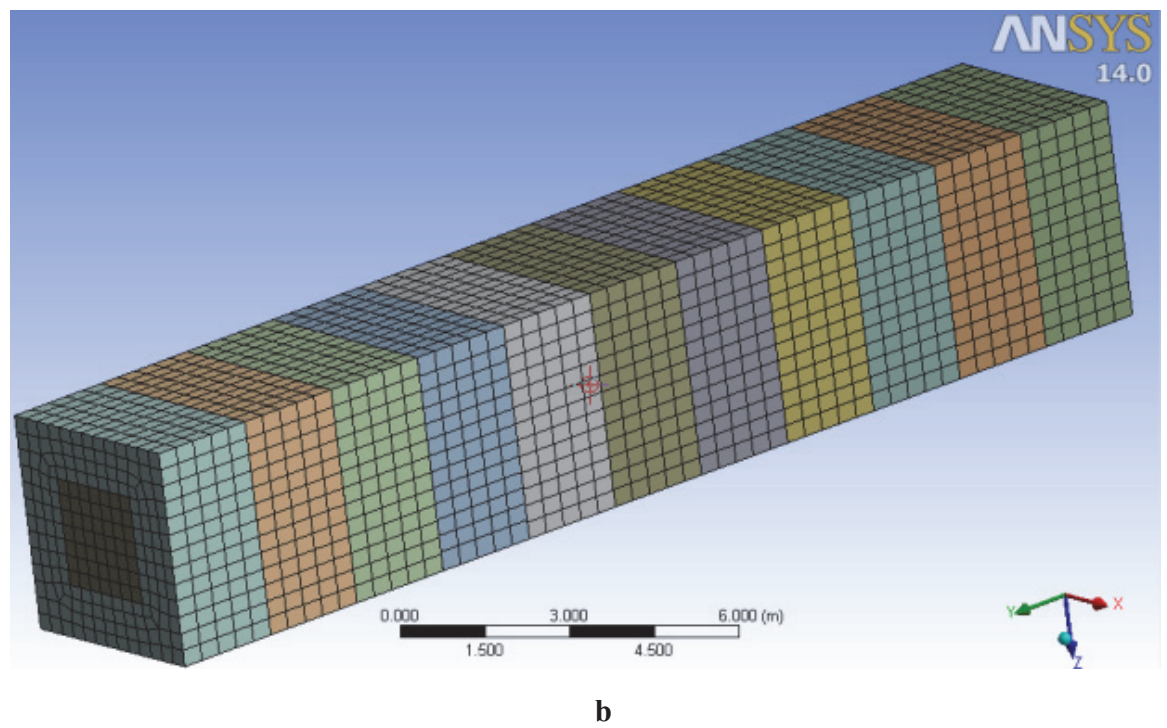

Fig. 5 - Control volume meshing: a) wireframe view, b) external faces view 


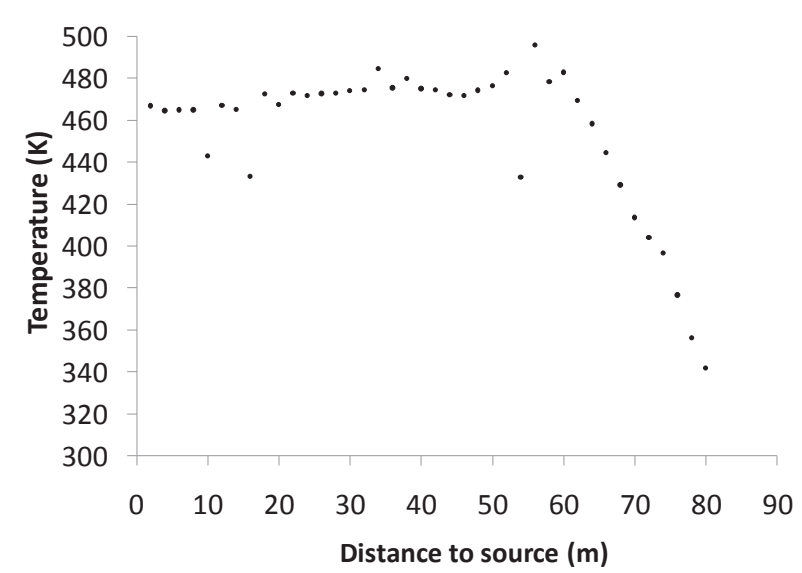

Fig. 6 - Temperature profile at explosions

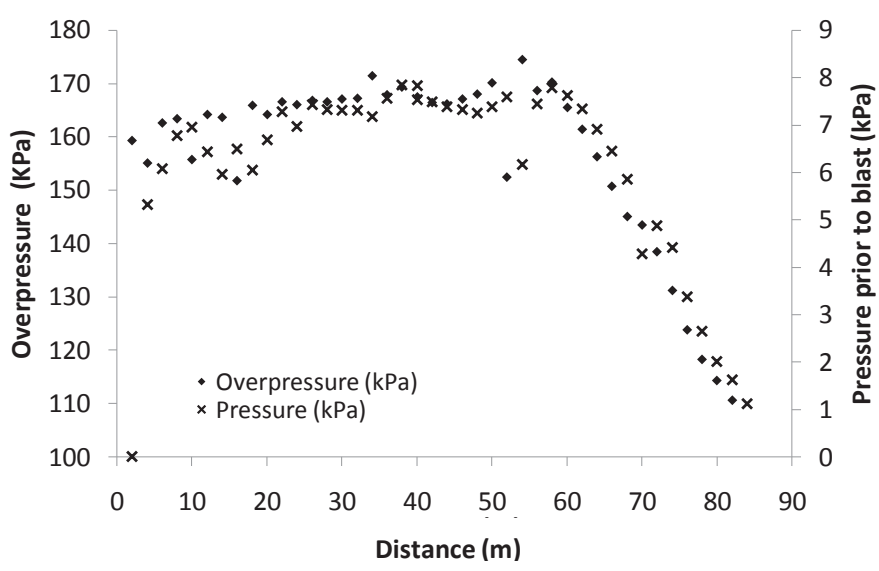

Fig. 7 - Profiles of pressure prior to blast and overpressure

computational time. This amount of control volumes represented a first step of the simulation. Simulations in stages started in the $3^{\text {rd }}$ control volume, whereas control volume 8 was the last stage simulation. Data for control volume 9 were placed in control volume 3 of the next stage. There were a total of 7 stages to cover the 40 simulated control volumes. The calculation time was $1500 \mathrm{~s}$ by simulating in a PC with $8 \mathrm{~GB}$ of RAM and processor Intel-i7 (R) $3.9 \mathrm{GHz}$.

The ASPEN package was used to calculate adiabatic reaction conditions. The first control volume obtained a temperature of reaction of $460 \mathrm{~K}$. This value for temperature did not exceed the self-ignition temperature for propane $(766 \mathrm{~K})$. For this reason, the onset of the reaction was taken as the moment of maximum pressure in the control volume to reproduce the worst potential effect. This maximum pressure was achieved in the first volume of control when time equalled $0.0034 \mathrm{~s}$. This time was produced in all simulations.

The results of the simulations included temperature profiles and overpressure. Figure 6 shows the temperature profile, which follows the trend of the propane fraction mass in the dispersion. This indicates a clear dependence of the temperature on the mass fraction of fuel as the mixture becomes leaner. Figure 7 describes the pressure in each control volume before the blast, as well as the maximum overpressure effect after the blast. These values result from the aerodynamic behavior of combustion gas inside control volumes. These profiles are independent of the cloud pressure profile during dispersion, Figure 4b. Both profiles follow the tendency of the fraction mass during the dispersion. This feature shows the dependence of the overpressure on the amount of mass.

Figure 8 represents the relationship between the pressure before the explosion and the overpressure. This relationship is linear and has greater values in zones with highest concentration in the cloud. A similar analysis was applied to the temperature before the explosion and temperature of the explosion. The relationship between both temperatures was similar to the relationship of pressures. Figure 9 shows the relationship between temperature prior to the explosion and temperature of the explosion. A high amount of points kept high temperature values.

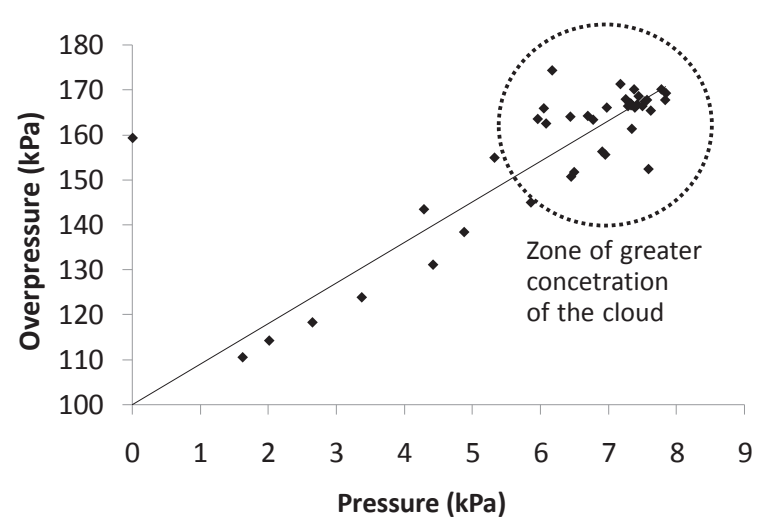

Fig. 8 - Comparative results for pressure prior to blast and overpressure

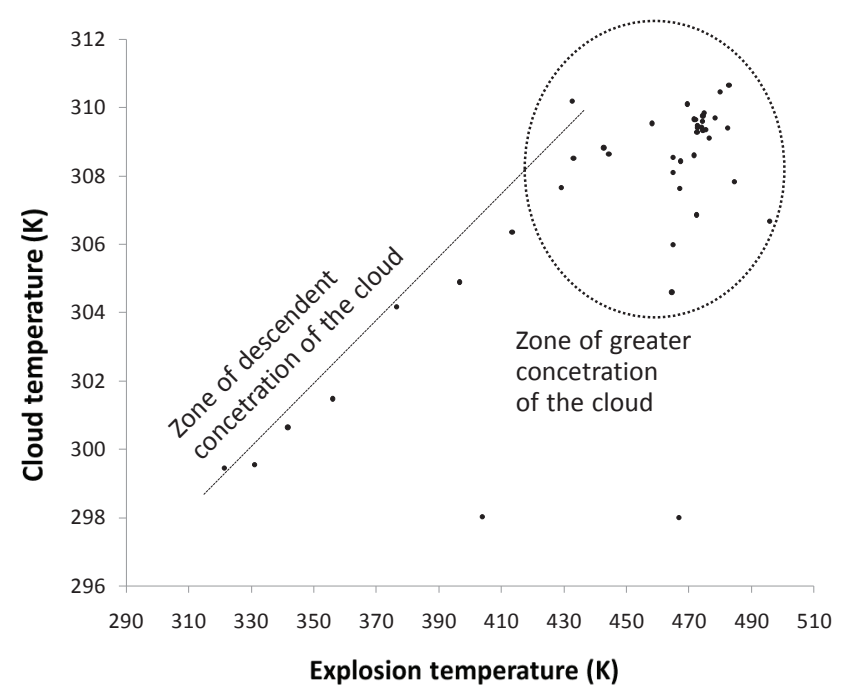

Fig. 9 - Comparative results for cloud temperature and explosion temperature 
Table 2 -Evolution of overpressure in the first five control volumes

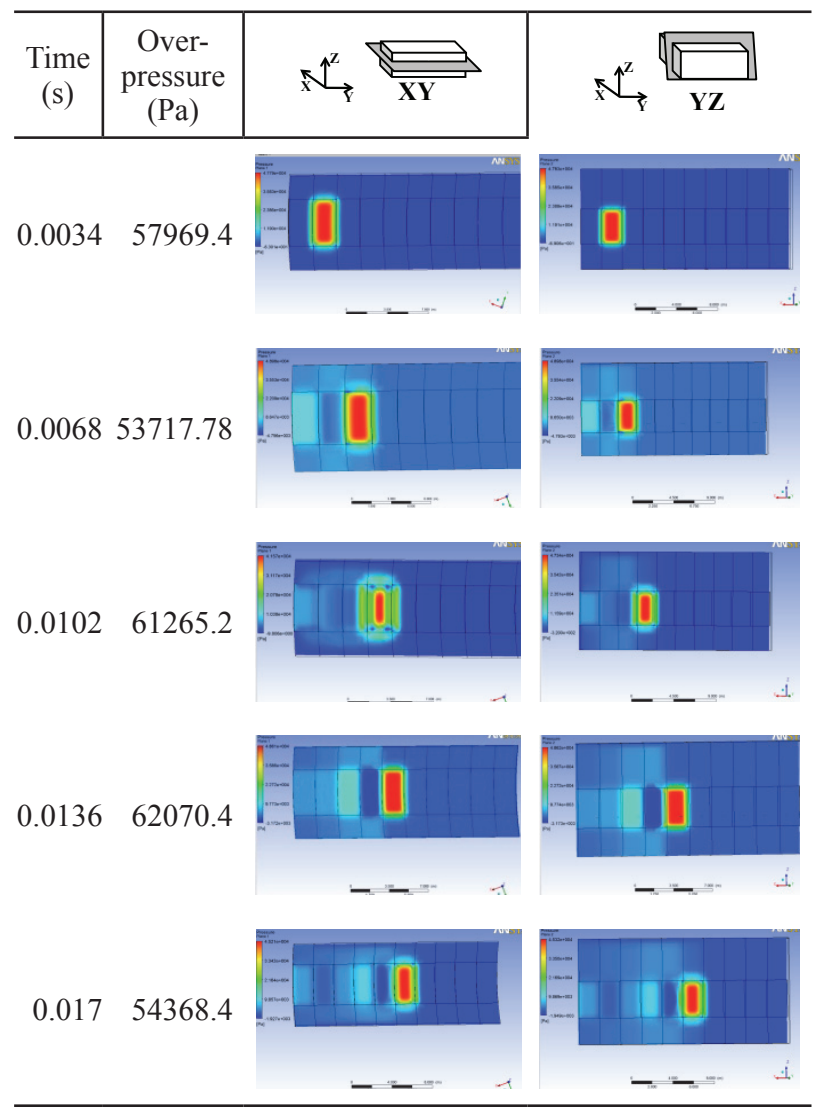

This set of points correspond to the area with highest concentration in the cloud.

The turbulence of the system generated oscillations in pressure prior to the explosion. Figure 10a represents these oscillations at different times of simulation. The oscillations increased in response to the generation of combustion gases. This is equivalent to the production of waves in different spots of standing water. Table 2 summarizes the evolution of the overpressure. The cutting layouts in Table 2 show symmetry, indicating a spherical pressure profile. Peaks in the overpressure at different times of simulation existed in different areas of explosion, Figure 10b. The explosion temperature presented an oscillatory behavior, Figure 11. This behavior is a result of the combustion gases movement and the increase in the energy released by the combustion.

A comparison between the overpressure curves obtained with CFX and calculated with TNO is necessary here, Figure 12. Unfortunately, the literature does not disclose a detailed description of the TNO values $^{31,32}$. The curve of the CFX simulation data seems to follow between levels 5 and 7. This indicates that there is no congestion effect between these levels, which agrees with our numerical experiment.
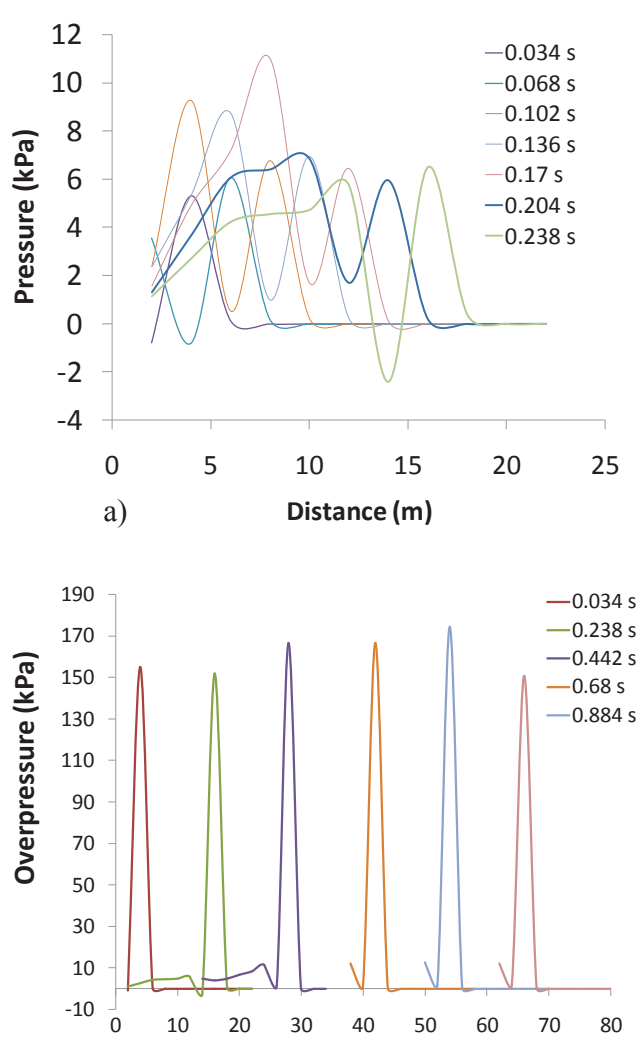

b)

Distance (m)

Fig. 10 - Profiles of pressure: a) oscillation of pressure, b) peak of overpressure

\section{Conclusions}

It seems that simplified models of explosion do not consider the turbulence effect. The package FLACS approximates this effect under a first-order reaction and applies a source of energy. The CFX tool demonstrated the rigorous turbulence effect during an explosion. The applied strategy considered simulation of consecutive explosions, assuming an adiabatic reaction without a source of energy.

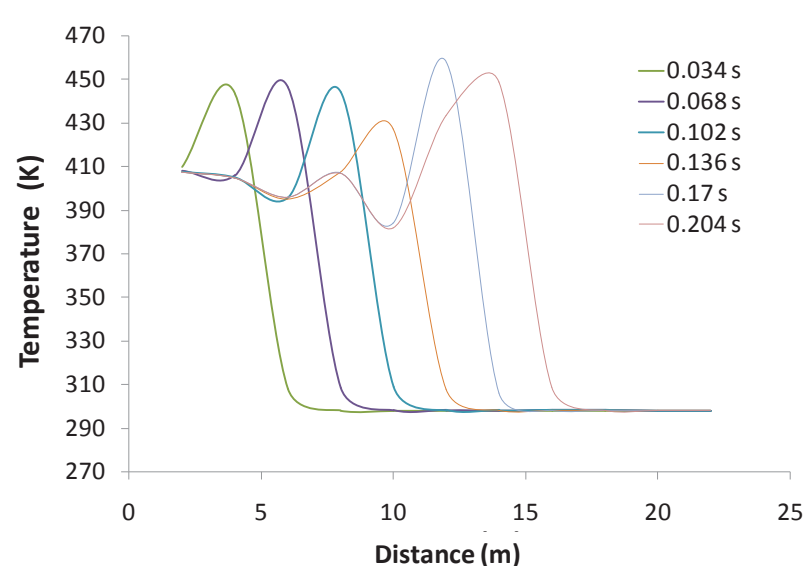

Fig. 11 - Temperature oscillations in different times 


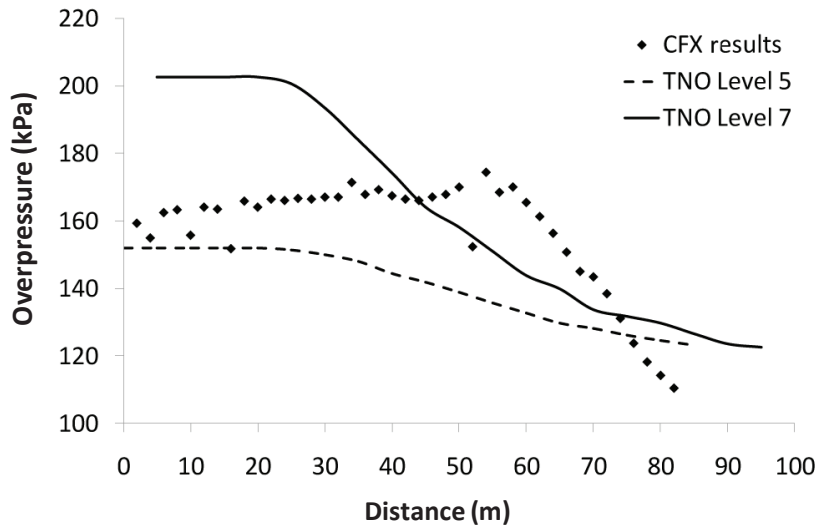

Fig. 12 - Comparison of CFX overpressure with results of TNO \#5 and \#7

This strategy has described the relationship between the intensity of the explosion and the amount of mass converted. The predicted behavior indicated by the TNO method fits very well with our approach where no congestion areas are considered, levels 5 and 6 of TNO, as indicated in that method. This methodology could be extended to describe explosions in systems with different levels of congestion.

\section{ACKNOWLEDGEMENTS}

The authors thank CONACyT for their support in this work.

\section{References}

1. Marsh-McLennan, The 100 largest losses (2012) 19722011.

2. Cozzani, V., Salzano, E., The quantitative assessment of domino effects caused by overpressure: Part I. Probit models, Journal of Hazardous Materials 107 (2004) 67. doi: https://doi.org/10.1016/j.jhazmat.2003.09.013

3. Crowl, D., Calculating the energy of explosion using thermodynamic availability, Journal of Loss Prevention in Process Industry 5 (1992) 109. doi: https://doi.org/10.1016/0950-4230(92)80007-U

4. Held, M., TNT-equivalent, Propellants, Explosives, Pyrotechnics 8 (1983) 158. doi: https://doi.org/10.1002/prep.19830080507

5. van den Berg, A. C., The multi-energy method: A framework for vapour cloud explosion blast prediction, Journal of Hazardous Materials 12 (1985) 1. doi: https://doi.org/10.1016/0304-3894(85)80022-4

6. Baker, Q. A., Doolittle, C. M., Fitzgerald, G. A., Tang, M. $J$., Recent developments in the Baker-Strehlow VCE Analysis methodology, Process Safety Progress 17 (1998) 297. doi: https://doi.org/10.1002/prs.680170411

7. Cormier, B. R., Qi, R., Yun, G., Zhang, Y., Mannan, M. S., Application of computational fluid dynamics for LNG vapor dispersion modeling: A study of key parameters, Journal of Loss Prevention in the Process Industries 22 (2009) 332.

doi: https://doi.org/10.1016/j.jlp.2008.12.004
8. Vasanth, S., Tauseef, S. M., Abbasi, T., Abbasi, S. A., Assessment of four turbulence models in simulation of largescale pool fires in the presence of wind using computational fluid dynamics (CFD), Journal of Loss Prevention in the Process Industries 26 (2013). doi: https://doi.org/10.1016/j.jlp.2013.04.001

9. Klippel, A., Schmidt, M., Muecke, O., Krause, U., Dust concentration measurements during filling of a silo and CFD modeling of filling processes regarding exceeding the lower explosion limit, Journal of Loss Prevention in the Process Industries 29 (2014) 122. doi: https://doi.org/10.1016/j.jlp.2014.02.006

10. Di Sarli, V., Russo, P., Sanchirico, R., Di Benedetto, A., CFD simulations of dust dispersion in the $20 \mathrm{~L}$ vessel: Effect of nominal dust concentration, Journal of Loss Prevention in the Process Industries 27 (2014) 8. doi: https://doi.org/10.1016/j.jlp.2013.10.015

11. Murillo, C., Dufaud, O., Bardin-Monnier, N., López, O., Munoz, F., Perrin, L., Dust explosions: CFD modeling as a tool to characterize the relevant parameters of the dust dispersion, Chemical Engineering Science 104 (2013) 103. doi: https://doi.org/10.1016/j.ces.2013.07.029

12. Ren, T., Wang, Z., Cooper, G., CFD modelling of ventilation and dust flow behaviour above an underground bin and the design of an innovative dust mitigation system, Tunnelling and Underground Space Technology 41 (2014) 241. doi: https://doi.org/10.1016/j.tust.2014.01.002

13. Fothergill, C. E., Chynoweth, S., Roberts, P., Packwood, A., Evaluation of a CFD porous model for calculating ventilation in explosion hazard assessments, Journal of Loss Prevention in the Process Industries 16 (2003) 341. doi: https://doi.org/10.1016/S0950-4230(02)00113-4

14. Rigas, F., Sklavounos, S., Experimentally validated 3-D simulation of shock waves generated by dense explosives in confined complex geometries, Journal of Hazardous Materials 121 (2005) 23. doi: https://doi.org/10.1016/j.jhazmat.2005.01.031

15. Rigas, F., Sklavounos, S., Simulation of Coyote series trials-Part II: A computational approach to ignition and combustion of flammable vapor clouds, Chemical Engineering Science 61 (2006) 1444. doi: https://doi.org/10.1016/j.ces.2005.09.005

16. Ferrara, G., Di Benedetto, A., Salzano, E., Russo, G., CFD analysis of gas explosions vented through relief pipes, Journal of Hazardous Materials 137 (2006) 654. doi: https://doi.org/10.1016/j.jhazmat.2006.03.037

17. Middha, P., Hansen, O. R., Grune, J., Kotchourko, A., CFD calculations of gas leak dispersion and subsequent gas explosions: Validation against ignited impinging hydrogen jet experiments, Journal of Hazardous Materials 179 (2010) 84. doi: https://doi.org/10.1016/j.jhazmat.2010.02.061

18. Qiao, A., Zhang, S., Advanced CFD modeling on vapor dispersion and vapor cloud explosion, Journal of Loss Prevention in the Process Industries 23 (2010) 843. doi: https://doi.org/10.1016/j.jlp.2010.06.006

19. Tauseef, S. M., Rashtchian, D., Abbasi, T., Abbasi, S. A., A method for simulation of vapour cloud explosions based on computational fluid dynamics (CFD), Journal of Loss Prevention in the Process Industries 24 (2011) 638. doi: https://doi.org/10.1016/j.jlp.2011.05.007

20. Dadashzadeh, M., Khan, F., Hawboldt, K., Amyotte, P., An integrated approach for fire and explosion consequence modelling, Fire Safety Journal 61 (2013) 324. doi: https://doi.org/10.1016/j.firesaf.2013.09.015 
21. Hansen, O. R., Hinze, P., Engel, D., Davis, S., Using computational fluid dynamics (CFD) for blast wave predictions, Journal of Loss Prevention in the Process Industries 23 (2010) 885 .

doi: https://doi.org/10.1016/j.jlp.2010.07.005

22. Hansen, O. R., Gavelli, F., Ichard, M., Davis, S. G., Validation of FLACS against experimental data sets from the model evaluation database for LNG vapor dispersion, Journal of Loss Prevention in the Process Industries 23 (2010) 857.

doi: https://doi.org/10.1016/j.jlp.2010.08.005

23. Gavelli, F., Davis, S. G., Hansen, O. R., Evaluating the potential for overpressures from the ignition of an LNG vapor cloud during offloading, Journal of Loss Prevention in the Process Industries 24 (2011) 908. doi: https://doi.org/10.1016/j.jlp.2011.07.002

24. Bakke, J. R., van Wingerden, K., Hoorelbeke, P., Brewerton, $B$., A study on the effect of trees on gas explosions, Journal of Loss Prevention in the Process Industries 23 (2010) 878. doi: https://doi.org/10.1016/j.jlp.2010.08.007

25. Hjertager, B. H., Computer simulation of turbulent reactive gas dynamics, Modeling, Identification and Control 5 (1985) 211.

doi: https://doi.org/10.4173/mic.1984.4.3

26. Popat, N. R., Catlin, C. A., Arntzen, B. J., Lindstedt, R. P., Hjertager, B. H., Solberg, T., Saeter, O., Van den Berg, A. $C$., Investigations to improve and assess the accuracy of computational fluid dynamic based explosion models, Journal of Hazardous Materials 45 (1996) 1. doi: https://doi.org/10.1016/0304-3894(95)00042-9

27. CCPS, Guidelines for evaluating characteristics of vapor cloud explosions, flash fires, and BLEVE's, Center for chemical process safety of the AIChE, New York, (1994).

28. $C P R$, Methods for the calculation of physical effects due to releases of hazardous materials (liquids and gases) "Yellow book", CPR 14E, 3rd ed., Ministerie van Verkeer en Waterstaat, Hague, Netherlands, (2005).

29. Wilcox, D. C., Turbulence Modeling for CFD, DCW Industries Inc., (2006).

30. Launder, B. E., Sharma, B. I., Application of the Energy-Dissipation model of turbulence to the calculation of flow near a spinning disc, Letters in Heat and Mass Transfer 1 (1974) 131. doi: https://doi.org/10.1016/0094-4548(74)90150-7

31. van den Berg, A. C., Lannoy, A., Methods for vapour cloud explosion blast modelling, Journal of Hazardous Materials 34 (1993) 151 doi: https://doi.org/10.1016/0304-3894(93)85003-W

32. Mercx, W. P. M., van den Berg, A. C., Hayhurst, C. J., Robertson, N. J., Moran, K. C., Developments in vapour cloud explosion blast modeling, Journal of Hazardous Materials 71 (2000) 301. doi: https://doi.org/10.1016/S0304-3894(99)00085-0 